\title{
Moment analysis of the flow-time curve after breathing gases of different densities
}

\author{
M R PARTRIDGE, A C WATSON, AND K B SAUNDERS \\ From the Department of Medicine, The Middlesex Hospital and Medical School, London
}

ABSTRACT In an attempt to improve methods of determining the site of airway narrowing we have tried using a heavier than air gas mixture $\left(\mathrm{SF}_{6} / \mathrm{O}_{2}\right)$ in addition to the more widely used lighter than air gas mixture $\left(\mathrm{He} / \mathrm{O}_{2}\right)$. Response to varying inspired gas density has been assessed by means of change in mean transit time (MTT) as well as by means of change in flow rate at $50 \%$ of vital capacity $\left(\dot{V}_{\max } \operatorname{mon}_{50}\right.$ ). The possibility that derivatives of second moment analysis of the flow time curve reflect the presence of small airway disease is studied. The reproducibility of response to $\mathrm{SF}_{6} / \mathrm{O}_{2}$ breathing was better than that to $\mathrm{He} / \mathrm{O}_{2}$ breathing. However there was no correlation between response to these two gas mixtures in either normal subjects or in patients with asthma. The response of MTT to $\mathrm{He} / \mathrm{O}_{2}$ breathing correlated with the response of $\dot{\mathrm{V}} \max _{50}$ and although no more reproducible, there are theoretical advantages in using MTT as the method of assessment. The derivative of the second moment of the flow-time curve, $\mathrm{COV}$, did not correlate with flow rate response to $\mathrm{He} / \mathrm{O}_{2}$ breathing.

Much of the clinical practice of respiratory medicine is concerned with patients with airway narrowing, and knowledge of the site of this narrowing within the airways may be helpful in understanding the pathogenesis of disease and in directing therapeutic efforts. However, methods of determining the major site of narrowing within the airways are imperfect. Measurement of airways resistance may reflect large airway calibre in normal subjects but in a patient with abnormal airways resistance it is impossible to say whether this is the result of a relatively small change in calibre of the large airways or a relatively large change in calibre of the small airways. Frequency dependence of compliance may be a good detector of inequal time constants in patients with minor degrees of peripheral airways disease but the technique is difficult to perform and poorly reproducible. ${ }^{1}$ Measurement of closing volume is useful in detecting isolated peripheral airway disease but once conventional tests of airway function become abnormal the gradient of phase 3 becomes much steeper and the closing volume is of ten not discernible. Bronchography has shown the site of antigeninduced airway narrowing in $\operatorname{dogs}^{2}$ but is an impractical method for widespread use in patients. While newly described radioaerosol and isotope imaging techniques ${ }^{3}$ show promise as methods of distinguishing between central and peripheral airway

Address for reprint requests: Dr MR Partridge, The London Chest Hospital. Bonner Road, London E2 9JX. narrowing, the most common accepted method is that of air and helium/oxygen $\left(\mathrm{He} / \mathrm{O}_{2}\right)$ flow volume curves, 45 and their theoretical background is supported by validation in dogs. ${ }^{6}$ Unfortunately, reproducibility of response of flow rates at $50 \%$ of vital capacity $\left(\operatorname{Vmax}_{50}\right)$ to $\mathrm{He} / \mathrm{O}_{2}$ breathing compares poorly with other standard physiological measurements. ${ }^{78}$ Furthermore the test is defining small airways as airways in which a laminar flow regime predominates and these may not correspond with the anatomical small airways (those with an internal diameter of less than $2 \mathrm{~mm}$ ), nor with the small airways detected by closing volume measurement (which are those which close on expiration), nor with the "small airways" in the sense of airways peripheral to the equal pressure point. ${ }^{9}$ Mink and colleagues $^{10}$ have recently suggested that in dogs laminar flow regimes may exist in airways up to $6 \mathrm{~mm}$ in diameter but nevertheless in situations of change measurement of air and $\mathrm{He} / \mathrm{O}_{2}$ flow volume curves may determine whether the change is occurring predominantly in the large central or in the smaller peripheral airways. The work of Brooks and colleagues ${ }^{11}$ suggests that the use of a denser than air gas may decrease variability. The first moment of the flow time curve, or mean transit time (MTT), ${ }^{12}$ (which may be obtained from the spirogram) may be useful in assessing the response to breathing gases of differing densities since it has the advantage of describing events throughout expiration by one 
number. Derivatives of the second moment of the flow-time curve have also been suggested as a method of determining the site of airway narrowing. ${ }^{13} 14$

In this study, therefore, we have attempted to assess the advantages of additional use of a denser than air gas mixture, sulphur hexafluoride/oxygen $\left(\mathrm{SF}_{6} / \mathrm{O}_{2}\right)$, and the value of assessing response to helium/oxygen $\left(\mathrm{He} / \mathrm{O}_{2}\right)$ breathing by measurement of MTT rather than $\operatorname{Vmax}_{50}$. We have also compared second moment derivatives with $\mathrm{He} / \mathrm{O}_{2}$ responsiveness of flow rates at $50 \%$ of vital capacity.

\section{Methods}

Ten normal subjects (non-smokers, seven men and three women, mean age 32.9 years) and 16 patients with symptomatic asthma took part in the study. Flow-volume curves were obtained using an Ohio 840 electronic spirometer from which flow and volume signals were taken to an Electronics for Medicine DR8 photographic recorder. From the spirometer, flow and volume signals were also taken to a multi-channel recorder allowing simultaneous recording of flow-time and volume-time curves. The participants performed a minimum of three forced expirations breathing air and results were accepted only if the vital capacity was reproducible to within $100 \mathrm{ml}$. Three further forced expirations were then performed after breathing $\mathrm{He} / \mathrm{O}_{2}(80 \% / 20 \%)$ until end-tidal nitrogen concentration was less than $5 \%$ when measured by a mass spectrometer (Centronics MGA 200). After washing out the helium by breathing room air the subject then took three relaxed vital capacity (VC) breaths of a $70 \% \mathrm{SF}_{6} / 30 \% \mathrm{O}_{2}$ mixture and performed three final maximum expiratory flowvolume manoeuvres. Flow rates at $50 \%$ of VC $\left(\dot{V}^{\prime} x_{50}\right)$ were measured at BTPS and the mean flow rate from at least three curves obtained breathing air was compared with those on $\mathrm{He} / \mathrm{O}_{2}$ and $\mathrm{SF}_{6} / \mathrm{O}_{2}$ and expressed as a percentage increase or decrease by the formula:

$\frac{\left(\dot{\mathrm{V}} \max _{50} \text { on } \mathrm{He} / \mathrm{O}_{2} \text { or } \mathrm{SF}_{6} / \mathrm{O}_{2}\right)-\left(\dot{\mathrm{V} m a x} \max _{50} \text { on air }\right)}{\left(\dot{\mathrm{V}} \max _{50} \text { on air }\right)} \%$

and also as described by Brooks and colleagues ${ }^{11}$

$$
\frac{\left(\dot{\mathrm{V}} \max _{50} \mathrm{He} / \mathrm{O}_{2}\right)-\left(\dot{\mathrm{V}} \max _{50} \mathrm{SF}_{6} / \mathrm{O}_{2}\right)}{\left(\dot{\mathrm{V}} \max _{50} \mathrm{SF}_{6} / \mathrm{O}_{2}\right)} \%
$$

For convenience the latter will subsequently be referred to as "Brooks factor". Flow rates every tenth of a second were measured manually from the flow-time curve, punched onto computer cards, and analysed as shown in the appendix to provide (1) mean transit time (MTT), which is derived from the first moment about the origin of the flow-time curve, and which indicates the average time taken by gas molecules in the lung to reach the mouth; and (2) the coefficient of variance (COV) which is derived from the second moment about the mean transit time and equals the $\frac{\text { standard deviation }}{\text { MTT }}$.

The COV indicates the spread or variation of transit times between the initial part of the vital capacity, which is expired quickly, and the slower terminal portion of the vital capacity. The effect of $\mathrm{He} / \mathrm{O}_{2}$ breathing upon MTT was assessed in the same manner as for $\dot{V} \max _{50}$.

Six of the patients had repeated measurements at different times with different degrees of airways obstruction and five of the normal subjects had measurements repeated at monthly intervals for three months to assess reproducibility. This was assessed within session and between session by means of the coefficient of variability $\left(\frac{\mathrm{SD}}{\text { Mean }} \times 100 \%\right)$.

\section{Results}

The table shows the results for normal subjects when breathing air, $\mathrm{He} / \mathrm{O}_{2}$, and $\mathrm{SF}_{6} / \mathrm{O}_{2}$ mixtures as assessed by flow rates measured from the flow-volume curve and by MTT and COV. As a group the patients with asthma had longer mean transit times breathing air (mean for 16 patients $=1.325$ ) and increased values for COV (Mean $=1 \cdot 191)$ when compared with the normal subjects. Figure 1 shows a comparison of the response of flow rates at $50 \% \mathrm{VC}$ to breathing $\mathrm{He} / \mathrm{O}_{2}$ (compared with air) with that to breathing $\mathrm{SF}_{6} / \mathrm{O}_{2}$ (compared with air). Results are included from 10 normal subjects studied on 20 occasions and the 16 patients with asthma studied on 26 occasions.

Figure 2 shows the percentage increase in $\dot{V}_{\max } 50$ breathing $\mathrm{He} / \mathrm{O}_{2}$ compared with air, plotted against the percentage shortening of MTT achieved by breathing the same mixture, again for normal subjects and patients with asthma.

The correlation coefficient ( $r$ ) between these two variables for normal subjects was $0.82(p<0.001$, slope $=-0 \cdot 46$, intercept $=-1 \cdot 35$ ), for the asthmatic patients and normal subjects together $r=0.61$. $(p<0.001$, slope $=-0.36$ intercept $=-5.45)$ and asthmatic patients alone $r=0.56(p<0.01$, slope $=$ -0.34 , intercept $=-6 \cdot 07)$. The weaker correlation among the patients with asthma was largely accounted for by the five "aberrant" results discussed below.

From fig 2 it can be seen that all the normal subjects and most all the patients were "responders" to $\mathrm{He} / \mathrm{O}_{2}$ breathing and a smaller number nonresponders by both methods. One patient who was studied soon after admission to hospital with acute asthma, showed a response to $\mathrm{He} / \mathrm{O}_{2}$ breathing as 


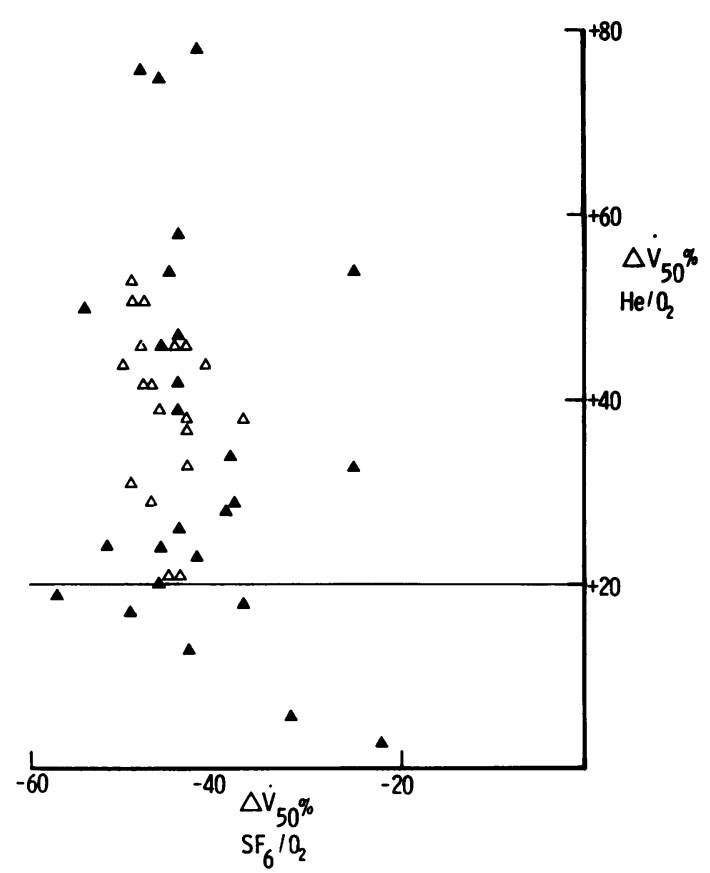

Fig 1 Percentage change in $\dot{V}_{\max } 50$ breathing $\mathrm{He} / \mathrm{O}_{2}$ (compared with air) plotted against percentage change in V'max ${ }_{50}$ breathing $S F_{6} / O_{2}$ (compared with air). The additional horizontal line indicates the division between responders and non-responders to $\mathrm{He} / \mathrm{O}_{2}$ breathing. $\triangle=$ normal subjects, $\Delta=$ asthma patients. judged by a shortening of mean transit time and an increase in V max, but had no corresponding increase in $\dot{V} \max _{50}$ or $\dot{V} \max _{25}$. The reason for this is not clear. Four patients showed "response" to $\mathrm{He} / \mathrm{O}_{2}$ breathing as judged by an increase in $\operatorname{V} \max _{50}$ but had only negligible shortening of their mean transit times. These four patients differed only in that they had extremely low values for $\dot{V} \max _{50}$ breathing air (mean $25.8 \%$ predicted, compared with a mean value for the other patients of $35.2 \%$ predicted). It is possible that the response of $\mathrm{V} \max 50$ to $\mathrm{He} / \mathrm{O}_{2}$ breathing is spurious in that an improvement of $\dot{V}^{2} a_{50}$ from for example 0.2 to $0.3 \mathrm{l} / \mathrm{s}$ would appear as a $50 \%$ change whereas a shortening of mean transit time from, for example, 2.0 to 1.8 would obviously not do likewise.

Figure 3 shows the percentage change in $\operatorname{Vmax}_{50}$ breathing $\mathrm{He} / \mathrm{O}_{2}$ (compared with air) plotted against $\mathrm{COV}$ derived from the second moment of the flowtime curve. There is no correlation between these two parameters and those who did not increase flow rates in response to $\mathrm{He} / \mathrm{O}_{2}$ breathing did not have the $\vec{\bullet}$ highest values for $\mathrm{COV}$.

\section{Discussion}

The response of $\dot{\mathrm{V} m a x} 50$ to $\mathrm{He} / \mathrm{O}_{2}$ and $\mathrm{SF}_{6} / \mathrm{O}_{2}$ breathing in normal subjects is similar to that reported by others, ${ }^{511}$ and the values for Brooks factor similar to those reported for other normal nonsmokers. ${ }^{11}$ Reproducibility of flow rate response to

Table Normal subjects. Mean values for a variety of indices, and reproducibility within session and at monthly intervals for three months

\begin{tabular}{|c|c|c|c|}
\hline & \multirow{2}{*}{$\begin{array}{l}\text { Mean results } \\
(\text { with SD) } \\
(n=10)\end{array}$} & \multicolumn{2}{|c|}{ Coefficient of variability $\%$} \\
\hline & & $\begin{array}{l}\text { Within session } \\
(n=10)\end{array}$ & $\begin{array}{l}\text { Monthly intervals } \\
(n=5)\end{array}$ \\
\hline Vmax breathing air (1/s) & $9 \cdot 28( \pm 1 \cdot 7)$ & $4 \cdot 0$ & $4 \cdot 8$ \\
\hline$\dot{V} \max _{50}$ breathing air $(1 / s)$ & $4.56( \pm 0.53)$ & $3 \cdot 0$ & $5 \cdot 6$ \\
\hline$\dot{\mathrm{V}}_{\max }{ }_{50}$ breathing $\mathrm{He} / \mathrm{O}_{2}(\mathrm{l} / \mathrm{s})$ & $6.44( \pm 0.72)$ & $4 \cdot 0$ & $8 \cdot 4$ \\
\hline$\dot{V} \max _{b 0}$ breathing $\mathrm{SF}_{6} / \mathrm{O}_{2}(1 / \mathrm{s})$ & $2.52( \pm 0.33)$ & $7 \cdot 2$ & $8 \cdot 1$ \\
\hline$\frac{\left(\dot{\mathrm{V} m a x} \max _{50} \mathrm{He} / \mathrm{O}_{2}\right)-\left(\dot{\mathrm{V}} \max _{50} \text { air }\right)}{\dot{\mathrm{V} m a x}} \%+$ & $+39.9( \pm 9 \cdot 46)$ & $*$ & $22 \cdot 5$ \\
\hline 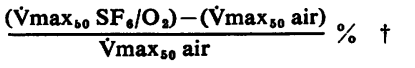 & $-44 \cdot 6( \pm 3 \cdot 34)$ & * & $5 \cdot 7$ \\
\hline 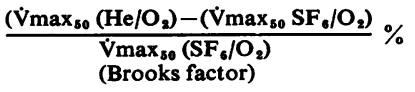 & $154 \cdot 3( \pm 29 \cdot 0)$ & $*$ & $14 \cdot 0$ \\
\hline MTT breathing air (s) & $0.584( \pm 0.089)$ & $6 \cdot 0$ & $6 \cdot 7$ \\
\hline MTT breathing $\mathrm{He} / \mathrm{O}_{2} \dagger$ (s) & $0.471( \pm 0.075)$ & $4 \cdot 2$ & $4 \cdot 5$ \\
\hline COV breathing air & $0.892( \pm 0.135)$ & $4 \cdot 4$ & $5 \cdot 4$ \\
\hline $\mathrm{COV}$ breathing $\mathrm{He} / \mathrm{O}_{\mathbf{2}} \dagger$ & $0.971( \pm 0.149)$ & $3 \cdot 7$ & $6 \cdot 2$ \\
\hline$\frac{(\text { MTT He/O })-(\text { MTT air })}{\text { MTT air }} \%$ & $-19.2( \pm 5.41)$ & * & $24 \cdot 1$ \\
\hline
\end{tabular}

* Results calculated by a comparison of mean of three recordings on each gas mixture, within-session reproducibility therefore not available. †Change compared with value breathing air statistically significant: $p<0.001$ paired $t$ test. 


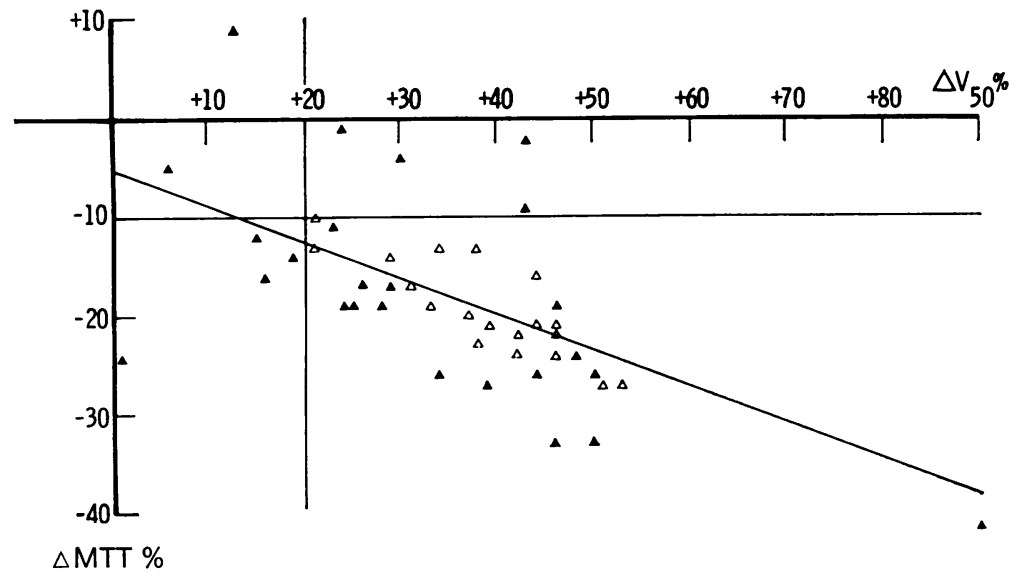

Fig 2 Percentage increase in $\dot{V} \max _{50}$ breathing $\mathrm{He}_{2} \mathrm{O}_{2}$ compared with air, plotted against the percentage shortening of MTT achieved by breathing the same mixture. The regression line is that for normal subjects and patients with asthma combined (see text). The additional horizontal and vertical lines encompass the results obtained from normal subjects, and the vertical line divides responders to $\mathrm{He} / \mathrm{O}_{2}$ breathing from non-responders. $\triangle=$ normal subjects, $\mathbf{\Delta}=$ asthma patients.

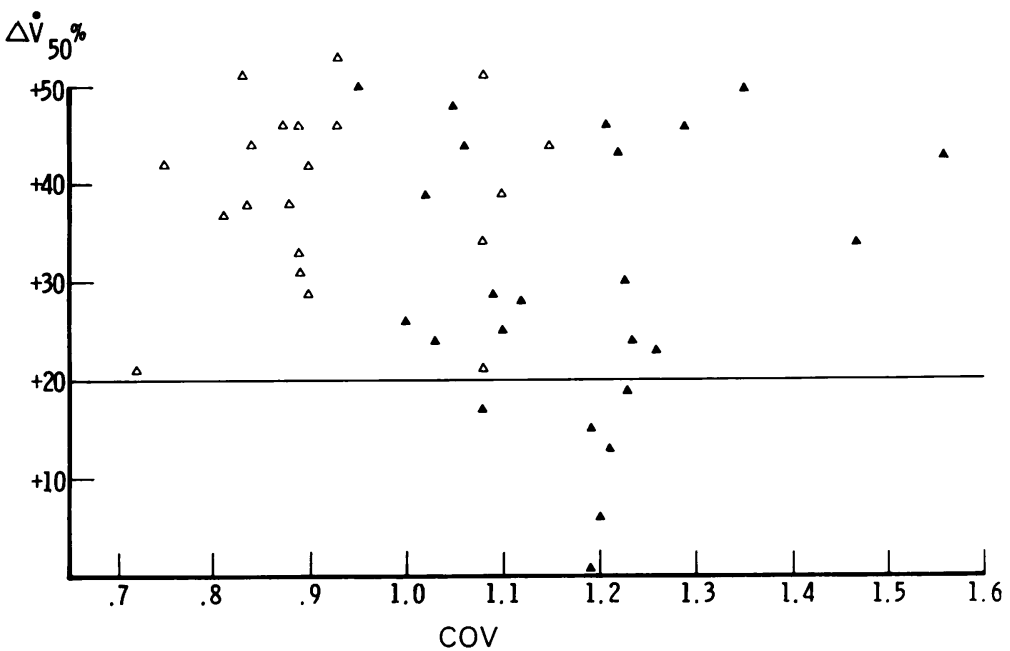

Fig 3 Percentage change in $\dot{V} \max _{50}$ breathing $\mathrm{He} \mathrm{O}_{2}$ (compared with air) plotted against COV (breathing air). The additional horizontal line represents the division between responders and non-responders to $\mathrm{He} / \mathrm{O}_{2}$ breathing. $\triangle=$ normal subjects, $\mathbf{\Delta}=$ asthma patients.

$\mathrm{He} / \mathrm{O}_{2}$ breathing in normal subjects studied at monthly intervals compared unfavourably with other standard physiological tests (table). However, a measurement that does not produce the same result on each occasion is not necessarily a bad test. In this context such a situation could arise because overall airways resistance did not change (and hence $\dot{V} \max$, $\dot{V} \max _{50}$, and $\dot{V} \max _{25}$ were approximately the same on each occasion) but the distribution of that resistance within the airways could be different on each occasion (and hence response to $\mathrm{He} / \mathrm{O}_{2}$ breathing different). We believe this to be a possible explanation for the apparent poor reproducibility of the test but in the absence of proof of this hypothesis the possible advantage of additionally assessing the effect of $\mathrm{SF}_{6} / \mathrm{O}_{2}$ on flow rates was explored.

$70 \% \mathrm{SF}_{6} / 30 \% \mathrm{O}_{2}$ was administered by means of three VC breaths because initial experiments showed
$80 \% \mathrm{SF}_{6} / 20 \% \mathrm{O}_{2}$ administered for longer periods to be narcotic and possibly hazardous to patients with limited reserves. ${ }^{15}$ The reproducibility of flow rates on $\mathrm{SF}_{6} / \mathrm{O}_{2}$ within session for normal subjects and patients was good and similar to that for $\mathrm{He} / \mathrm{O}_{2}$ even at monthly intervals. However the coefficient of variation of percentage change in flow rates on $\mathrm{SF}_{6} / \mathrm{O}_{2}$ compared to air was better than that of $\mathrm{He} / \mathrm{O}_{2}(5.7 \%$ vs $22.5 \%)$ and hence when results were expressed as Brooks factor ${ }^{11}$ the coefficient of variability was similarly better $(14.0 \%)$ than that for the helium-air density dependence $(22 \cdot 5 \%)$.

Thus far the use of $\mathrm{SF}_{6} / \mathrm{O}_{2}$ appeared promising. However, when the effect of $\mathrm{SF}_{6} / \mathrm{O}_{2}$ on $\dot{\mathrm{V}} \max _{50}$ in normal subjects and in patients with asthma was compared with the effect of $\mathrm{He} / \mathrm{O}_{2}$ there was no correlation (fig 1). With $\mathrm{He} / \mathrm{O}_{2}$ there was marked interindividual variability as one would expect if the 
major site of airflow limitation was differing between subjects. However, the response to $\mathrm{SF}_{6} / \mathrm{O}_{2}$ breathing was more uniform and those who had not altered their flow rates on $\mathrm{He} / \mathrm{O}_{2}$ usually did so on $\mathrm{SF}_{6} / \mathrm{O}_{2}$.

The reason for this lack of correlation is not clear but it is likely that the greater difference in density between air and $\mathbf{S F}_{6}$ than that between air and helium $^{16}$ disguises real differences between individuals. In those who were responders to $\mathrm{He} / \mathrm{O}_{2}$ breathing because of the greater difference in density between air and $\mathrm{SF}_{6}$, flows are reduced more by $\mathrm{SF}_{6}$ than they are increased by helium. The fact that the reduction in flow rates on $\mathrm{SF}_{6} / \mathrm{O}_{2}$ was consistent despite variations in response to $\mathrm{He} / \mathrm{O}_{2}$ is in part because a $50 \%$ increase in flow is not one of the same absolute magnitude as a $50 \%$ reduction, and in part because there is a more obvious endpoint to a reduction in flow than there is hypothetically to an increase in flow. If this explanation is correct it must also explain why some non-responders to $\mathrm{He} / \mathrm{O}_{2}$ breathing reduced their flow rates on $\mathrm{SF}_{6} / \mathrm{O}_{2}$. In these patients most of upstream resistance ${ }^{9}$ originates in airways in which a laminar flow regime independent of density predominates. ${ }^{4}$ However, even in such situations upstream resistance may include a component from airways with turbulent flow and even in the predominantly laminar flow airways some eddying occurs at bifurcations. Thus changes in density can presumably have some effect, which is not great when a moderate change in density is made (ie $\mathrm{He} / \mathrm{O}_{2}$ given), but becomes apparent when a large change in density of inspired gas is made.

It is possible that a lesser increase in density than that of $70 \% \mathrm{SF}_{6} / 30 \% \mathrm{O}_{2}$ may produce a change more comparable to that of $\mathrm{He} / \mathrm{O}_{2}$ (eg $40 \% \mathrm{SF}_{6}$, $40 \% \mathrm{~N}_{2}, 20 \% \mathrm{O}_{2}$ ). This requires study but it is possible that the single advantage of $\mathrm{SF}_{6}$ shown by these studies (that of better reproducibility) may then be lost, for this reduction in inter and intraindividual variability may be caused entirely by the overpowering effect of the very dense $\mathrm{SF}_{6}$. Either way in these studies the $\mathrm{SF}_{6} / \mathrm{O}_{2}$ response did not correlate with that to $\mathrm{He} / \mathrm{O}_{2}$ and did not distinguish normal subjects from any patients with asthma.

When comparing flow rates breathing air with those breathing $\mathrm{He} / \mathrm{O}_{2}$ no consistent differences in response have been shown between results obtained at the same time from exhaled flow-volume curves and those obtained in a plethysmograph. ${ }^{17}$ However when comparing flow rate response to $\mathrm{He} / \mathrm{O}_{2}$ breathing at different times or after drugs when there may be significant changes in vital capacity, $\dot{V} \max _{50}$ may be difficult to interpret if absolute lung volumes are not measured. Under such circumstances although flow rates at $50 \%$ of exhaled VC are being compared each time, because of changes in residual volume and total lung capacity the absolute lung volume at which measurements are being made may well be different. Theoretically this source of error can only be overcome by the use of a Mead type plethysmograph, ${ }^{18}$ but serial studies in a plethysmograph-for example, after exercise,- -are often impractical. While mean transit time is also derived from an exhaled vital capacity and like the exhaled flow volume curve takes no account of thoracic gas compression or changes in residual volume, it does have the advantage that it is reflecting emptying characteristics of a much greater lung volume rather than just the flow rate at one lung volume ( $\left.\mathrm{eg} \operatorname{Vimax}_{50}\right)$.

Hypothetically, assessment of response to $\mathrm{He} / \mathrm{O}_{2}$ breathing by means of MTT analysis, therefore, has advantages over assessment by means of change in flow rates at $50 \%$ of exhaled VC.

While standard equations were used, the method of calculation of moments used in this study differs from that used by others, ${ }^{13} 141920$ being based on the flow-time curve rather than the volume-time curve. This was because we had no online computer and preliminary studies showed that it was easier manually to digitise the flow-time curve than the volume-time curve. Our method produced results for derivatives of moment analysis which were almost identical to those found in normal subjects by others. ${ }^{19} 20$

The results show that there was a statistically significant correlation between the effect of $\mathrm{He} / \mathrm{O}_{2}$ breathing upon MTT and its effect upon Vंmax ${ }_{50}$ in both normal subjects and in patients with asthma (fig 2). A few aberrant results were shown but as explained it is possible that these were related to the difficulties of measurement of very low flow rates $\stackrel{0}{x}$ and the expression of change in terms of percentage $\frac{0}{3}$ increase. The assessment of response to $\mathrm{He} / \mathrm{O}_{2}$ breathing by change in MTT, therefore, not only has the advantage of encompassing events over a much larger lung volume but additionally, because $ᄋ$ it often involves numerically larger figures, obviates $\rightarrow$ problems of interpretation of changes in very low flow rates. However, intra-subject variability of response of MTT to $\mathrm{He} / \mathrm{O}_{2}$ breathing over a three- $\sigma$ month period (table) was no better than that for $N$ $\dot{V} \max _{50}$ suggesting that the variability truly reflects $\underset{\omega}{\mathrm{N}}$ physiological change rather than being caused $O$ purely by difficulties of single volume measurement. 0

Several workers ${ }^{14}{ }^{19}$ have suggested that increased $\stackrel{\odot}{\varnothing}$ values for $\mathrm{COV}$ reflect the presence of small airways $\stackrel{\infty}{+}$ disease and theoretically a greater component of $\underline{T}$ slowly emptying peripheral units would cause a $\stackrel{\vec{D}}{\circ}$

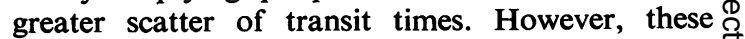
workers' reasons for suggesting that an increase in $\stackrel{\mathbb{Q}}{\varnothing}$ COV represents small airways disease are open to question. In 18 normal subjects given $\mathrm{He} / \mathrm{O}_{2}$ Macfie 
and colleagues ${ }^{19}$ noted a shortening of MTT (compared with air) of a similar magnitude to that shown in our normal subjects (table). In their studies, however, although COV increased a mean $5.4 \%$ on $\mathrm{He} / \mathrm{O}_{2}$ this change was not statistically significant. They inferred from this that as $\mathrm{He} / \mathrm{O}_{2}$ was reducing the resistance in large airways, and as this change did not significantly affect COV then any change in COV must reflect a change in the small airways. In our normal subjects on the other hand the $9.1 \%$ increase in $\mathrm{COV}$ on $\mathrm{He} / \mathrm{O}_{2}$ (table) was significant, suggesting that $\mathrm{COV}$ is also affected by changes in the large airways.

By correlating MTT and COV with various indices which they regarded as reflecting large (airways resistance and $\dot{\mathrm{V}} \max )$ or small $\left(\dot{\mathrm{V}} \max _{25}\right)$ airway disease and placing weight on strength of correlation coefficients, Neuberger and colleagues ${ }^{14}$ suggested that MTT reflects change in both large and small airways whereas COV reflects peripheral changes. However, the assumption that in patients with abnormalities of lung function airways resistance depends on large airways and $\dot{V} \max _{25}$ depends on small airways is questionable. Furthermore, if an increase in value of $\mathrm{COV}$ reflects an increased component of small airway disease and if poor response of $\dot{\mathrm{V} m a x} 50$ to $\mathrm{He} / \mathrm{O}_{2}$ breathing reflects the same there should be a correlation between these two parameters. Figure 3 shows that this is not the case. We believe that the position with COV is possibly analogous with that of frequency dependence of compliance or closing volume measurement. It may be sensitive to minor peripheral abnormalities of ventilatory function when these occur alone, but when more overt large and small airway disease is present it may not act as an index of regional narrowing.

These results do not suggest that the derivatives of moment analysis as used here, or the additional use of $\mathrm{SF}_{6} / \mathrm{O}_{2}$ offer an improvement on the current methods of determining the site of narrowing within the airways. However, assessment of response to $\mathrm{He} / \mathrm{O}_{2}$ by means of MTT analysis has theoretical advantages over assessment by means of changes in $\dot{V} \max _{50}$ with which it correlates.

MRP was in receipt of a Sir Jules Thorn Research Fellowship and the study was supported by an equipment grant from the British Heart Foundation. This work forms part of a thesis submitted by MRP to the University of Manchester for the degree of MD.

\section{References}

1 Guyatt AR, Siddorn IA, Brash HM, Flenley DC. Reproducibility of djnamic compliance and flow- volume curves in normal man. J Appl Physiol 1975; 39, 341-8.

2 Kessler GF, Austin JHM, Graf PD, Gamsu G, Gold WM. Airway constriction in experimental asthma in dogs: tantalum bronchographic studies. $J$ Appl Physiol 1973; 35:703-8.

3 Chopra SK, Taplin GC, Tashkin DP, Trevor E, Elam D. Imaging sites of airway obstruction and measuring functional responses to bronchodilator treatment in asthma. Thorax 1979; 34:493-500.

4 Despas PJ, Leroux M, Macklem PT. Site of airway obstruction in asthma as determined by measuring maximal expiratory flow breathing air and a HeliumOxygen mixture. J Clin Invest 1972; 51:3235-43

5 Dosman J, Bode F, Urbanetti J, Martin R, Macklem PT. The use of a Helium-Oxygen mixture during maximum expiratory flow to demonstrate obstruction in small airways in smokers. $J$ Clin Invest 1975; 55:1090-9.

6 Barnett TB. Effects of helium and oxygen mixtures on pulmonary mechanics during airway constriction. $J$ Appl Physiol 1967; 22:707-13.

7 Loveland M, Corbin R, Ducis S, Martin RR. Evaluation of the analysis and variability of the Helium response. Bull Europ Physiopath Respir 1978; 14:551-60.

8 Macdonald JB, Cole TJ. The flow-volume loop: reproducibility of air and helium-based tests in normal subjects. Thorax 1980; 35:64-9.

9 Mead J, Turner JM, Macklem PT, Little JB. Significance of the relationship between lung recoil and maximum expiratory flow. J Appl Physiol 1967; 22:95-108.

10 Mink S, Ziesmann M, Wood LDH. Mechanisms of increased maximum expiratory flow during $\mathrm{He} / \mathrm{O}_{2}$ breathing in dogs. J Appl Physiol 1979; 47:490-502.

11 Brooks SM, Zipp T, Barber M, Carson A. Measurements of maximal expiratory flow rates in cigarette smokers and non-smokers using gases of high and low densities. Am Rev Respir Dis 1978; 118:75-81.

12 Pride NB. Analysis of forced expiration - a return to the recording spirometer? Thorax 1979; 34:144-9.

13 Liang A, Macfie AE, Hari is EA, Whitlock RML. Transit-time analysis of the forced expiratory spirogram during clinical remission in juvenile asthma. Thorax 1979; 34:194-9.

14 Neuberger N, Levison H, Kruger K. Transit time analysis of the forced expiratory vital capacity in cystic fibrosis. Am Rev Respir Dis 1976; 114:753-9.

15 Liese W, Fitzgerald MXM, Cumming G. Analysis of the time factor in flow-volume curves of normal subjects and patients with chronic obstructive bronchitis. Respiration 1972; 29:214-22.

16 Cotes JE. Lung function - assessment and application in medicine. Fourth edition. Blackwell Scientific Publications, Oxford; 1979: 80.

17 Benatar SR, Clark TJH, Cochrane GM. Clinical relevance of the flow rate response to low density gas breathing in asthmatics. Am Rev Respir Dis 1975; 111:126-34.

18 Mead J. Volume displacement body plethysmograph 
for measurements in human subjects. J Appl Physiol $1960 ; 15: 736-40$.

19 Macfie AE, Harris EA, Whitlock RML. Transit-time analysis of the forced spirogram in healthy children and adults. J Appl Physiol 1979; 46:263-7.

20 Jordanoglou J, Koursouba E, Lalenis C, Gotsis T, Kontos J, Gardikas C. Effective time of the forced expiratory spirogram in health and airways obstruction. Thorax 1979; 34:187-93.

21 Permutt S, Menkes HA. Spirometry: analysis of forced expiration within the time domain. In: Macklem PT, Permutt S, eds. The lung in the transition between health and disease. New York: Marcel Dekker, 1979; 113-52.

\section{Appendix}

If flow $\dot{V}$ during a forced expiratory manoeuvre is recorded against time, the flow value at any given moment is proportional to the number of gas molecules passing the flow meter at that moment. The start of expiration is taken as time zero, or the origin of the flow-time and volumetime (spirogram) curves.
Following Permutt and Menkes ${ }^{21}$ the nth moment of $\overrightarrow{\vec{F}}$ time about an arbitrary point a during a forced expiration

is defined as $\mu^{1}{ }_{n}=\frac{\int_{0}^{a}(t-a)^{n} \dot{V} \mathrm{dt}}{\int_{0}^{a} \dot{V} \mathrm{dt}}=\frac{\int_{0}^{a}(\mathrm{t}-\mathrm{a})^{\mathrm{n}} \dot{\mathrm{V}} \mathrm{dt}}{\mathrm{VC}}$

where VC is the vital capacity.

If we use $a_{n}$ as the nth moment about the origin $(a=0), \vec{\circ}$ then $\alpha_{1}$ is the mean transit time ( $\left.\overline{\mathrm{t}}\right)$. If $\mu_{\mathrm{n}}$ is the nth moment about the mean transit time, $\mu_{2}$ is the variance of transit times, $\sqrt{\mu_{2}}$ is the standard deviation and $\sqrt{\mu_{2} / a_{1}}$ is the coefficient of variation (COV).

We have calculated $a_{1}$ and $\sqrt{\mu_{2} / a_{1}}$ direct from the flow- $\omega_{O}$ time curve, estimating the integrals by measuring flow every tenth of a second, where $\alpha_{1}$, or $\overline{\mathrm{t}}$, the mean transit time

$$
\begin{aligned}
= & \frac{\int_{\mathrm{c}}^{a} \mathrm{t} \cdot \dot{\mathrm{V}} \mathrm{dt}}{\mathrm{VC}} \\
\text { and } \mu_{2} & =\frac{\int_{0}^{a}(\mathrm{t}-\overline{\mathrm{t}})^{2} \dot{\mathrm{V}} \mathrm{dt}}{\mathrm{VC}}
\end{aligned}
$$

